polymer grows homogeneously in the monomer crystal. Epitactic polymerization been mentioned, and I feel that electron diffraction should have been treated more fully.

In Part C ("Physical Properties') the authors have apparently assumed that they were to write about polymers in bulk. This is an unfortunate limitation in an otherwise techniques yield valuable data when applied to dilute polymer solutions. Plazek's excellent chapter on viscoelastic and steady-state rheological response would have benefited from the inclusion of experimental data; it is most surprising that the dependence of polymer viscosity on chain length and temperature is not mentioned. Also, Rutherford and Brown might have discussed the effect of the rate is another phenomenon which might have excellent volume, since a number of the

of loading on stress-strain measurements and Hay's treatment of polymer orientation could have included a mention of anisotropic polymer solutions. The chapter on polymer alloys stresses excessively cohesive energy density, which is known to be inadequate in predicting polymer compatibility. As for the chapters on the electrical behaviour of polymers, I wish that polymer conductivity had received a fuller treatment and that the important phenomenon of piezoelectricity had been at least mentioned.

However, the various criticisms detailed above should in no way detract from the value of this survey. The books should be part of the library of every serious polymer scientist.

Herbert Morawetz is Director of the Polymer Research Institute at the Polytechnic Institute of New York.

\section{The philosophy of geochemistry}

\section{Arthur W. Rose}

Environmental Geochemistry: A Holistic Approach. Ecological Studies, Vol.35. By John A.C. Fortescue. Pp.347. (SpringerVerlag: 1980.) DM 69, $\$ 40.80$.

Although this book is entitled Environmental Geochemistry, its main emphasis is on landscape geochemistry and related aspects of geochemistry in the surficial zone of the Earth. Landscape geochemistry deals with the chemical interactions between rocks, the atmosphere, natural waters and living organisms, and thus furnishes the geochemical background for many environmental problems. Most previous discussion of the subject has been by Russians, notably A.I. Perel'man. A major contribution of this book is to summarize the Russian approach and results, which are referred to throughout the text.

The opening chapters describe landscape geochemistry in broad outline and also the purpose of the book, which is to introduce a general approach and mode of thinking for conducting environmental geochemical studies and for comparing results from different areas; the history and concepts of landscape geochemistry are summarized (geochemical cycles, landscape prisms, landscape types, mobility of elements), together with the permutations and complications created by space, time, chemical complexity and varying scientific effort.

Each of the important concepts and principles of landscape geochemistry is then discussed in detail. These include element abundance in rocks, waters, plants, animals and air, and the speciation of these elements into abundances of different form (exchangeable, acid extractable and so on); element migration varying conditions; geochemical flows by various types of surface and near-surface transport; geochemical gradients such as decrease of chemical content away from an orebody or pollution source, and climatically controlled gradients; geochemical barriers formed by changes in chemical environment along a flow path, resulting in precipitation and accumulation of selected elements; historical geochemistry, leading to recognition of changes in chemistry with time; and geochemical classification of landscapes. These chapters include many tables giving basic geochemical data and numerous examples and figures from environmental and exploration geochemical studies.

The book concludes with an interesting chapter on practical applications of landscape geochemistry which illustrates uses in geochemical exploration for minerals, environmental pollution, waste disposal, plant and animal nutrition, and geoepidemiology. An integrated view of all elements in a landscape prism and of changes with time and space is stressed throughout.

The author has a philosophical and pedagogical approach to his subject, and ideas and information rather than the information itself. Most experienced environmental and exploration geochemists are probably familiar with many or all of the concepts discussed, but the book draws from a diverse background, and all those investigating chemical processes on the Earth's surface will probably gain new ideas from the book.

Arthur W. Rose is Professor of Geochemistry at The Pennsylvania State University and is coauthor of Geochemistry in Mineral Exploration (Academic Press, 1979). or relative mobility of elements under repeatedly emphasizes the organization of

\section{Taxonomy is far from boring}

\section{Otto Kandler}

Microbiological Classification and Identification. The Society for Applied Bacteriology Symposium Series, No 8. Edited by $M$. Goodfellow and R. G. Board. Pp.408. (Academic: 1980.) £20, $\$ 46$.

CLASSIFICATION and identification is often considered to be a boring, old-fashioned subject dealing with the simple morphological and physiological properties of organisms. This volume, however, dernonstrates the opposite. The 15 papers, presented by leading experts at the 1978 SAB symposium at Birmingham, describe the highly sophisticated applications of the most advanced biochemical and molecular biological principles and techniques for exploring and determining new taxonomical characters. They do not, however, give detailed prescriptions on how to carry out the identification of a particular organism, nor do they contain phylogenetic trees or keys for the classification of particular taxa or groups of bacteria. Since none of the contributions cover viruses or fungi, the reader may feel somewhat misled by the term "microbiological" used in the title.

One paper deals with the principles of computer-aided numerical taxonomy in a way quite understandable to the nonmathematician. Others are concerned with the application of DNA-DNA hybridization and with the role of neutral mutations, insertion sequence elements and plasmids in the genotypic variability of bacteria. Aspects of fine-structure research and cell wall and lipid chemistry are also dealt with. In addition, papers are devoted to the applicability of enzyme and protein patterns of various kinds and to the chemical analysis of fermentation products. The suitability of serological methods is discussed with respect to their use in detecting food-poisoning toxins, the ability of phage-typing with respect to the classification of plant-pathogenic bacteria, and the usefulness of determining enzyme activities is exemplified by the identification of clinical specimens.

Apart from the omission of viruses and fungi, there are other gaps - I looked in vain for a concise contribution on the implications of sequence analysis of proteins and nucleic acids for the classification of taxa above the species level. Altogether, though, this volume will be most informative for advanced students and research workers in bacterial taxonomy; it will, however, not cover the everyday needs of the clinical or food bacteriologist.

Otto Kandler is a Professor at the Botanisches Institut der Universität, Munich. 